Egyptian

Orthodontic Journal

\title{
EVALUATION OF CARIES SUSCEPTIBILITY AFTER INTERPROXIMAL ENAMEL REDUCTION
}

\author{
Mohamed Sherif M. S. Farag* \\ Ahmed El Sayed A. Salama*
}

ABSTRACT

Studies of the caries susceptibility of stripped proximal surfaces have produced some what varying results. We aimed in this study to highlight on the effect of anterior interproximal enamel reduction on caries susceptibility and to evaluate if topical application of fluoride is needed or not. This study was conducted on 28 patients with mean age $13.3 \pm 0.74$ years. They were all caries free with good gingival condition. They were divided into 4 equal groups; group 1: had no orthodontic treatment, group 2: had fixed orthodontic treatment without interproximal reduction, group 3: had fixed orthodontic treatment after anterior interproximal reduction and group 4: had fixed orthodontic treatment after anterior interproximal reduction followed by topical application of sodium fluoride. They were all instructed to follow proper oral hygiene methods. It was found that there was no caries development in the four groups till the end of the 3 years follow up period. It was concluded that well controlled interproximal enamel reduction may not be a caries risk factor.

\section{INTRODUCTION}

Interproximal enamel reduction is a commonly used method to alleviate crowding in the permanent dention ${ }^{(1)}$. Studies have shown that $7 \mathrm{~mm}$ of space can be predictably created with $50 \%$ reduction of the enamel thickness of the premolars and the first molars with an additional gain of $2.5 \mathrm{~mm}$ if the anterior

\footnotetext{
* Lecturer of Pediatric and Preventive Dentistry, Faculty of Dentistry, Suez Canal University

${ }^{* *}$ Lecturer of Orthodontics, Faculty of Dentistry, Girls Section, AlAzhar University.
} 
dentition is also included ${ }^{(2,3)}$. Stripping has the advantage over extraction therapy of a significant reduction in treatment time, since the amount of tooth structure removed corresponds exactly to the amount of crowding.

Further, the preserved intercanine width and broaded contact surface can help in prevention of posttreatment relapse ${ }^{(4)}$. Potential adverse effects such as periodontal problems associated with root proximity and development of interarch tooth-mass discrepancy, when stripping is limited to one arch, had been found to be of a little clinical significance. ${ }^{(2)}$ But interproximal enamel reduction had been limited by the potential caries risk of the abraded enamel surface ${ }^{(5)}$.

It seems impossible to completely polish stripped interproximal surfaces using conventional methods. In a study by El Manguory et al., ${ }^{(6)}(1991)$, they concluded that the roughness produced by stripping did not predispose to caries. Indeed, remineralization appeared after nine months. Many studies also stated that constant remineralization occurs naturally ${ }^{(7,8,9)}$.

Their findings substantiate those of other studies that found no increased susceptibility to caries after stripping ${ }^{(10,11,12)}$. Others still encourage the topical application of fluoride after stripping ${ }^{(13)}$. Others concluded that there is little concern over caries development when the mandibular incisors are slenderized as these rarely develop caries ${ }^{(10,14)}$.

Aim of the study: We aimed to highlight on the effect of anterior interproximal enamel reduction on caries susceptibility, and to evaluate if topical application of fluoride is needed or not.

\section{Materials and Methods}

This study was carried out on a sample of 28 patients with mean age $13.3 \pm 0.74$ years at the beginning of the study. All subjects had a routine caries screening and were considered caries-free at baseline prior to the initiation of orthodontic treatment. During treatment the patients were instructed to come at regular 6 months intervals for routine care. All patients were subjected to full-mouth clinical and radiographic caries assessments.

\section{They were divided into 4 groups:}

1- Group 1: Passive control group: they were 7 patients with mean age $13.5 \pm 0.5$ years. They had not any orthodontic treatment.

2- Group II: Positive control group: they were 7 patients with mean age $13 \pm 0.9$ years. They had fixed orthodontic treatment without lower anterior interproximal enamel reduction. 
3- Group III and IV: (Study groups): they were 14 patients. They had crowding in the anterior lower permanent teeth and treatment for each one needed interproximal enamel reduction from 1.75 to $2.5 \mathrm{~mm}$.

For each subjects in Group III and IV the following was done after proper diagnosis:

1- Proximal reduction to six lower anterior teeth from 0.125 to $0.25 \mathrm{~mm}$ for each surface according to degree of crowding using very fine tapered bur(699L stripping bur) ${ }^{*}$ followed by finishing stone (135-EF Stiletto-shaped ultra fine finishing diamond stone) ${ }^{*}$

2 - Interproximal finishing and polishing using polishing abrasive strips ${ }^{* *}$

3- Placement of the orthodontic brackets and wires as indicated for orthodontic treatment. The patients' teeth were examined for having intact buccal enamel, no cracks, no caries. The teeth were cleaned and polished with pumice and rubber prophylactic cups for 10 seconds.

Brackets were placed using a 0.22 " inch slot, Roth type brackets ${ }^{* * *}$ and were used for treatment for all patients.

Bonding ${ }^{* * * *}$ was done according to manufacturer instructions supplied with each product by one operator. The curing time was 40 seconds (10 seconds on each mesial, distal, occlusal and gingival margin of the brackets) using a visible light-curing unit (intensity $480 \mathrm{~nm}$ ).

All the patients were going the normal sequence of routine orthodontic work, starting from $0.012^{2}$ round NiTi up to $0.016^{2}$ X $0.022^{2}$ St.St. wires ${ }^{* * *}$

4- For group IV only ( 7 patients) with mean age ( $13 \pm 0.7$ years), 4 topical applications of $5 \%$ sodium fluoride solution, one week interval and repeated every six months for the three years follow up period. While no fluoride application was done for group III (7 patients) with mean age (13.4 \pm 0.8$)$ years, they were asked to use brush with their usual tooth paste.

\section{Follow up period:}

Group II, III and IV were under fixed orthodontic treatment for $1.5 \pm 0.5$ year. All the four groups were instructed how to brush their teeth properly with

${ }^{*}$ Dentsply Ltd, Ash Instrument, U. K.

${ }^{* *}$ Viking, Finishing Strips, Brazil

${ }^{* * *}$ American Orthodontics, Sheboygan, WI, U.S.A.

${ }^{* * * *}$ Relay A bond, Ralliance, U.S.A. 
any tooth paste. After finishing orthodontic treatment brackets had been removed using bracket removing plier ${ }^{* * *}$, excess composite was removed with a small scaler followed by polishing with a fine finishing stone*.

They were recalled each six months to detect presence of caries. Clinically, caries detection was performed with a fine tip explorer with the operative light as the sole source of illumination. A surface was considered carious if it was soft upon tactile exploration and if the instrument bound to the cavitated area. Caries on each surface was recorded as present or absent regardless of its extent.

\section{RESULTS}

This study was conducted on 28 children with mean age $13.3 \pm 0.74$ years at the beginning of the study. They were divided into 4 groups.

Clinical examination of all the proximal surfaces for the four groups revealed no softness upon tactile exploration and no instrument binding to any cavitated area.

These findings indicated that there were no carious lesions detected in any of the subjects under examination in all the four tested groups.

\section{DISCUSSION}

Interproximal enamel reduction is a commonly used method to alleviate crowding in the permanent dention ${ }^{(1)}$. Interproximal enamel reduction had been limited by the potential caries risk of the abraded enamel surface ${ }^{(5)}$. We aimed to highlight on the effect of anterior interproximal enamel reduction on caries susceptibility, and to evaluate if topical application of fluoride is needed or not.

The 28 children were nearly of the same age. They were all caries free to be sure that the only caries risk factor was the orthodontic treatment and the other complicating risk factor was the interproximal enamel reduction. It was found in this study that there is no caries development for either the passive control group, or the positive control group with fixed orthodontic treatment, or the study groups with interproximal enamel reduction with or without topical application of fluoride. Similar findings were found by many studies ${ }^{(10,11,12,5)}$. Other studies stated that constant remineralization occurs naturally ${ }^{(7,8,9)}$.

\section{CONCLUSION}

It was concluded that well controlled interproximal enamel reduction might not be a caries risk factor. 
Egyptian

Orthodontic Journal

\section{REFERENCES}

1. Sheridan J.J.: Air-rotor stripping. J Clin Orthod. 19: 43-59. (1985).

2. Sheridan J.J.: Air-rotor stripping update. J Clin Orthod. 27: 781-788. (1987).

3. Stroud J.L., English J. and Buschang P.H.: Enamel thickness of the posterior dentition its implications for nonextraction treatment. Angle Orthod. 68 : 141-146. (1988).

4. Artun J., Kokich V.G. and Osterberg S.K.: Long-term effect of root proximity on periodontal health after orthodontic treatment. Am J Orthod Dentofacial Orthop. 91 : 125-130. (1987).

5. Jarjoura K., Gagnon G. And Nieberg L.: Caries risk after interproximal enamel reduction. Am J Orthod Dentofacial Orthop. 130 : (1) 26-30. (2006).

6. El-Mangoury N.H., Moussa M.M., Mostafa Y.A. and Girgis A.S.: In vivo remineralization after air-rotor stripping. J Clin Orthod. 75-78. (1991).

7. Begg P.R.: Stone age man`s dentition. Am J. Orthod. 40:298-312. (1954).

8. Wolpoff M.H.: Interstitial wear. Am J Phys. Anthropol. 34:205-228. (1971).

9. Hinton R.J.: Form and pattern of anterior tooth wear among aboriginal human groups. Am J Phys. Anthropol. 54:555-564. (1981).

10. Bose L.R.: Fiberotomy and reproximation without lower retention : Nine years in retrospect. Angle Orthod. 50:88-97, 169-178. (1980).

11. Radlanski R.J. Jager A., Schwestka R. and Bertzbach F.: Plaque accumulation caused by interdental stripping. Am J Orthod. 94: 416-420. (1989).

12. Crain G. and Sheridan J.J.: Susceptibility to caries and periodontal disease after posterior air-rotor stripping. J Clin Orthod. 24:84-85. (1990).

13. Carter R.N.: Reproximation and recontouring made simple. J Clin Orthod. 23: 636-637. (1989).

14. Twesme D.A., Firestone A.R., Heaven T.J., Feagin F.F. and Jacobson A.: Air-rotor stripping and enamel demineralization in vitro. Am J Orthod. 142-152. (1994). 